
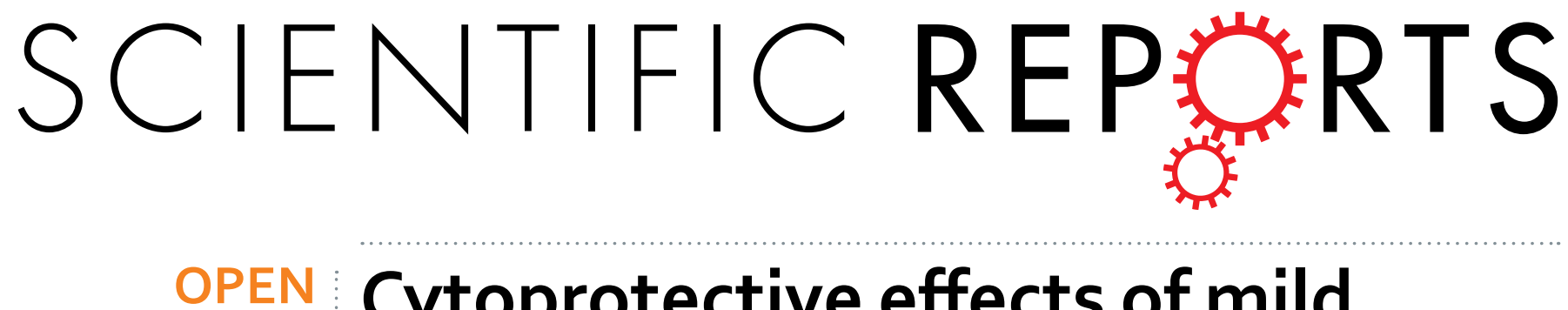

\title{
Cytoprotective effects of mild plasma-activated medium against oxidative stress in human skin
}

Received: 07 October 2016 Accepted: 03 January 2017

Published: 07 February 2017 fibroblasts

\author{
Minori Horiba, Tetsuro Kamiya, Hirokazu Hara \& Tetsuo Adachi
}

Non-thermal atmospheric pressure plasma (NTAPP) has recently been applied to living cells and tissues and has emerged as a novel technology for medical applications. NTAPP affects cells not only directly, but also indirectly with previously prepared plasma-activated medium (PAM). The objective of this study was to demonstrate the preconditioning effects of "mild PAM" which was prepared under relatively mild conditions, on fibroblasts against cellular injury generated by a high dose of hydrogen peroxide $\left(\mathrm{H}_{2} \mathrm{O}_{2}\right)$. We observed the preconditioning effects of mild PAM containing approximately $50 \mu \mathrm{M}$ $\mathrm{H}_{2} \mathrm{O}_{2}$. Hydrogen peroxide needs to be the main active species in mild PAM for it to exert preconditioning effects because the addition of catalase to mild PAM eliminated these effects. The nuclear translocation and recruitment of nuclear factor erythroid 2-related factor 2 ( $\mathrm{Nrf2}$ ) to antioxidant response elements (ARE) in heme oxygenase 1 (HO-1) promoters and the up-regulation of $\mathrm{HO}-1$ were detected in fibroblasts treated with mild PAM. The addition of ZnPP, a HO-1-specific inhibitor, or the knockdown of Nrf2 completely abrogated the preconditioning effects. Our results demonstrate that mild PAM protects fibroblasts from oxidative stress by up-regulating $\mathrm{HO}-1$, and the $\mathrm{H}_{2} \mathrm{O}_{2}$-induced activation of the Nrf2ARE pathway needs to be involved in this reaction.

Plasma is the fourth state of matter and is defined as an ionized gas. According to its gas temperature, plasma has been divided into thermal and non-thermal plasma. Non-thermal atmospheric pressure plasma (NTAPP) has recently been applied to living cells and tissues ${ }^{1}$ and has emerged as a novel technology for clinical medicine, for example, wound healing ${ }^{2}$, blood coagulation ${ }^{3}$, sterilization ${ }^{4}$, and cancer treatments $s^{1,5,6}$. In these studies on its clinical application, a low dose of NTAPP was reported to induce the proliferation of cells, whereas a high dose induced apoptosis? ${ }^{7}$. NTAPP contains variable compositions of ultraviolet light, free electrons, and charged particles as well as reactive oxygen species (ROS) such as the hydroxyl radical $(\bullet \mathrm{OH})$, superoxide $\left(\mathrm{O}_{2}^{-}\right)$, ozone $\left(\mathrm{O}_{3}\right)$, and hydrogen peroxide $\left(\mathrm{H}_{2} \mathrm{O}_{2}\right)$, and reactive nitrogen species (RNS) including nitric oxide $(\mathrm{NO} \bullet$ ) and peroxynitrite $\left(\mathrm{ONOO}^{-}\right)^{8,9}$. Most of the functions of NTAPP are involved in the activities of ROS and/or RNS ${ }^{10-12}$.

ROS affect several signaling pathways in cells such as protein kinases, transcription factors, and cellular signaling proteins ${ }^{13}$. High levels of intracellular ROS are known to be harmful because they trigger significant oxidative damage in cellular macromolecules, such as nucleotides, lipid, and proteins, whereas low levels of intracellular ROS are necessary for a number of important physiological functions including intracellular signal transduction and host defenses against microorganisms ${ }^{14}$. "Preconditioning" is a phenomenon in which brief oxidative stress induced by low levels of ROS may result in protection against a subsequent stronger stress. The Kelch-like ECH-associated protein 1 (Keap1)-nuclear factor erythroid 2-related factor 2 (Nrf2)-antioxidant response element (ARE) signaling pathway is one of the important ROS-induced physiological functions maintaining cellular redox homeostasis ${ }^{15}$. Under normal conditions, Nrf2 is rapidly trapped by Keap1 in the cytoplasm and degraded by ubiquitin-dependent proteolysis. On the other hand, with increases in the levels of electrophilic compounds including ROS, Keap1 is inactivated via the oxidation of its cysteine residues and dissociates Nrf2. Therefore, Nrf2 is stabilized and translocated to the nucleus, and then binds to ARE, a cis-regulatory DNA sequence located in the promoter of target genes encoding phase II detoxifying enzymes, and cytoprotective proteins including heme oxygenase $1(\mathrm{HO}-1)^{16,17}$. Among various $\mathrm{ROS}, \mathrm{H}_{2} \mathrm{O}_{2}$ is known to activate $\mathrm{Nrf}^{18-20}$. 


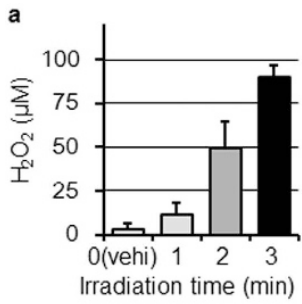

b

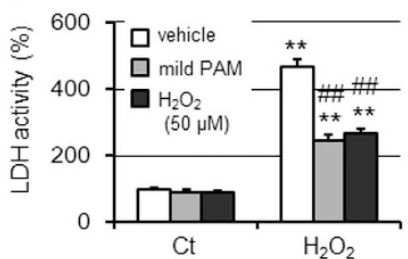

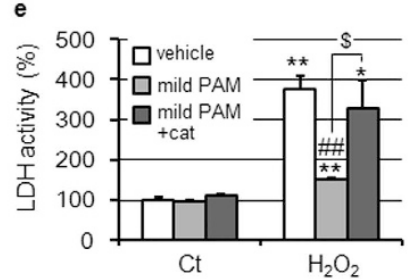

$\mathrm{Ct}$

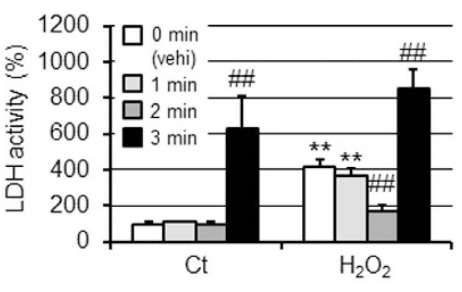

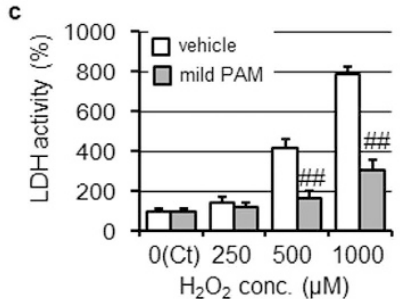

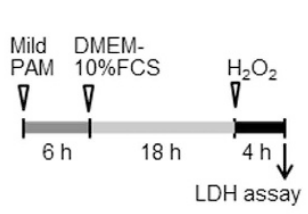

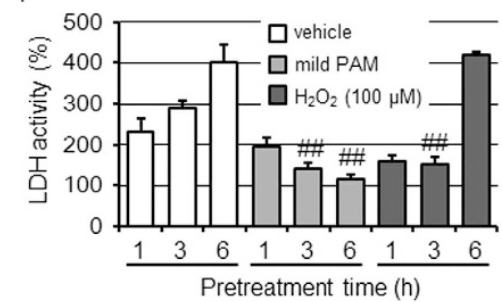
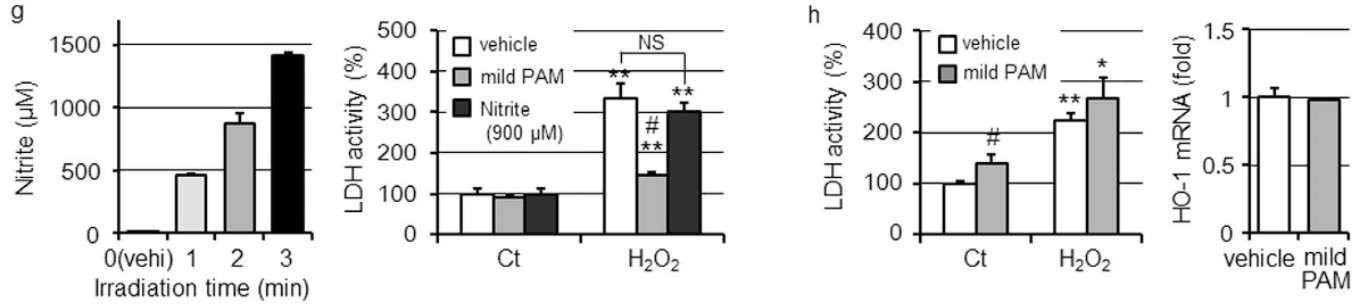

Figure 1. Pretreatment with mild PAM reduced $\mathrm{H}_{2} \mathrm{O}_{2}$-induced cell injury. (a) Concentrations of $\mathrm{H}_{2} \mathrm{O}_{2}$ in mild PAM prepared by the irradiation of NTAPP for the indicated times. $(\mathbf{b}$, left) Experimental procedure; fibroblasts were pretreated with mild PAM for $6 \mathrm{~h}$ in a $\mathrm{CO}_{2}$ incubator. After the exchange of mild PAM to DMEM-10\% FCS, fibroblasts were cultured for $18 \mathrm{~h}$ in a $\mathrm{CO}_{2}$ incubator. Fibroblasts were then treated with $500 \mu$ $\mathrm{M} \mathrm{H}_{2} \mathrm{O}_{2}$ in DMEM for $4 \mathrm{~h}$ in a $\mathrm{CO}_{2}$ incubator, followed by an assay for $\mathrm{LDH}$ released into conditioned medium. (b, right) Fibroblasts were pretreated with mild PAM prepared by the irradiation of NTAPP for the indicated times. Control (Ct) fibroblasts were incubated with DMEM for $4 \mathrm{~h}$ instead of $500 \mu \mathrm{M} \mathrm{H}_{2} \mathrm{O}_{2}$ in DMEM. (c) After the pretreatment with mild PAM or DMEM (vehicle), and followed by the incubation with DMEM-10\% FCS, fibroblasts were treated with DMEM with or without 250, 500, and $1000 \mu \mathrm{M} \mathrm{H}_{2} \mathrm{O}_{2}$ for $4 \mathrm{~h}$, followed by the LDH assay. (d) Fibroblasts were pretreated with mild PAM, $50 \mu \mathrm{M} \mathrm{H}_{2} \mathrm{O}_{2}$ in DMEM, or DMEM (vehicle) for $6 \mathrm{~h}$, followed by the procedure described above. (e) Fibroblasts were treated with mild PAM in the presence or absence of catalase $(50 \mathrm{U} / \mathrm{mL}$ ) or DMEM (vehicle) for $6 \mathrm{~h}$, followed by the procedure described above. (f) Fibroblasts were treated with mild PAM, $100 \mu \mathrm{M} \mathrm{H}_{2} \mathrm{O}_{2}$ in DMEM, $500 \mu \mathrm{M} \mathrm{H}_{2} \mathrm{O}_{2}$ in DMEM, or DMEM (vehicle) for the indicated times, followed by the procedure described above. (g, left) Concentrations of nitrite in mild PAM prepared by irradiation with NTAPP for the indicated times. (g, right) Fibroblasts were pretreated with mild PAM, $900 \mu \mathrm{M}$ nitrite in DMEM, or DMEM (vehicle) for $6 \mathbf{h}$. (h, left) A549 cells were pretreated with mild PAM or DMEM (vehicle) for $6 \mathrm{~h}$, followed by the procedure described above. (h, right) A549 cells were treated with mild PAM or DMEM (vehicle) for $6 \mathrm{~h}$, and HO-1 mRNA levels were then measured. Data are shown as the mean $\pm \mathrm{SD}(\mathrm{n}=3),{ }^{*} p<0.05,{ }^{* *} p<0.01$ vs. the control, ${ }^{*} p<0.05,{ }^{\# \#} p<0.01$ vs. vehicle, ${ }^{\$} p<0.05$, NS not significant.

NTAPP has been reported to affect cells not only directly, but also indirectly with previously prepared plasma-activated medium (PAM) ${ }^{6,21-23}$. The relatively short-lived ROS and RNS produced in medium by NTAPP irradiation are converted to other relatively long-lived species such as $\mathrm{H}_{2} \mathrm{O}_{2}$, nitrite/nitrate (NOx), and other unknown species ${ }^{21,24,25}$. PAM has recently been shown to induce apoptosis in cancer cells $s^{6,25-30}$. On the other hand, the effects of PAM prepared under relatively mild conditions, termed mild PAM, on normal cells are currently unclear. The stimulation of Phase II antioxidant pathways in keratinocytes by PAM has recently been reported ${ }^{31}$.

The objective of this study was to demonstrate the preconditioning effects of mild PAM on fibroblasts against cellular injury generated by a high dose of $\mathrm{H}_{2} \mathrm{O}_{2}$ as an oxidative stress inducer and elucidate the involvement of the Keap1-Nrf2-ARE signaling pathway in this cytoprotection.

\section{Results}

Reductions in $\mathrm{H}_{2} \mathrm{O}_{2}$-induced cell injury by the pretreatment with mild PAM. NTAPP irradiation produced $\mathrm{H}_{2} \mathrm{O}_{2}$ in DMEM in irradiation time-dependent manners under our experimental conditions, as shown in Fig. 1a. In the present study, fibroblasts were treated with mild PAM for $6 \mathrm{~h}$ and then incubated with culture medium for $18 \mathrm{~h}$. Fibroblasts were then treated with $500 \mu \mathrm{M} \mathrm{H}_{2} \mathrm{O}_{2}$ as strong oxidative stress for $4 \mathrm{~h}$, as shown in Fig. $1 \mathrm{~b}$ left panel, except in specifically described experiments. Cell injury induced by the treatment with $500 \mu \mathrm{M}$ 
$\mathrm{H}_{2} \mathrm{O}_{2}$ was significantly suppressed by the pretreatment with mild PAM prepared by plasma irradiation for $2 \mathrm{~min}$, whereas mild PAM prepared by irradiating for $1 \mathrm{~min}$ did not affect cell injury, as shown in Fig. $1 \mathrm{~b}$ right panel. On the other hand, (mild) PAM prepared by irradiating for $3 \mathrm{~min}$ induced cell injury, even without the $\mathrm{H}_{2} \mathrm{O}_{2}$ treatment. Fibroblasts pretreated with mild PAM significantly resisted cytotoxicity induced by $\mathrm{H}_{2} \mathrm{O}_{2}$ at concentrations of 500 or $1000 \mu \mathrm{M}$ (Fig. 1c). $\mathrm{H}_{2} \mathrm{O}_{2}$ is known to be the main active species in PAM $^{24-27}$, and mild PAM prepared by an irradiation time for 2 min contained approximately $50 \mu \mathrm{M} \mathrm{H}_{2} \mathrm{O}_{2}$, as shown in Fig. 1a. The pretreatment with $50 \mu \mathrm{M} \mathrm{H}_{2} \mathrm{O}_{2}$-supplemented DMEM provided a similar degree of suppression against $\mathrm{H}_{2} \mathrm{O}_{2}$-induced cellular injury to mild PAM (Fig. 1d). Moreover, fibroblasts pretreated with mild PAM supplemented with catalase $(50 \mathrm{U} / \mathrm{ml})$ did not resist cell injury (Fig. 1e). The preconditioning effects of mild PAM depend on its $\mathrm{H}_{2} \mathrm{O}_{2}$ concentration and pretreatment time. Cell injury was significantly and maximally suppressed by the pretreatment with mild PAM for $6 \mathrm{~h}$ and followed by $3 \mathrm{~h}$, as shown in Fig. $1 \mathrm{f} \mathrm{left} \mathrm{panel.} \mathrm{On} \mathrm{the} \mathrm{other} \mathrm{hand,} 100 \mu \mathrm{M} \mathrm{H}_{2} \mathrm{O}_{2}$-supplemented DMEM, the $\mathrm{H}_{2} \mathrm{O}_{2}$ concentration of which was the same as that of (mild) PAM prepared by NTAPP irradiation for 3 min, exerted preconditioning effects by the pretreatment for $3 \mathrm{~h}$. However, cell injury was induced by the pretreatment for $6 \mathrm{~h}$. The pretreatment with $500 \mu \mathrm{M} \mathrm{H}_{2} \mathrm{O}_{2}$-supplemented DMEM, the $\mathrm{H}_{2} \mathrm{O}_{2}$ concentration of which was similar to that of PAM used in previous studies ${ }^{25,27,28}$, for $30 \mathrm{~min}$ suppressed the release of LDH (Fig. $1 \mathrm{f}$ right). However, cells detached from the culture dish following the pretreatment with $500 \mu \mathrm{M} \mathrm{H}_{2} \mathrm{O}_{2}$-supplemented DMEM for $3 \mathrm{~h}$.

Another main species in mild PAM is NOx, and NTAPP irradiation for 2 min produced approximately $900 \mu \mathrm{M}$ nitrite as NOx (Fig. 1g left). However, the pretreatment with $900 \mu \mathrm{M}$ nitrite-supplemented DMEM did not reduce cell injury (Fig. 1g right).

We previously reported that a PAM treatment effectively induced apoptosis in A549 human lung adenocarcinoma epithelial cells ${ }^{25,27,28}$. When A549 cells were treated with mild PAM according to the protocol shown in Fig. $1 \mathrm{~b}$ left, mild PAM led to slightly greater cell injury than that with the vehicle, as shown in Fig. 1h left panel.

Induction of HO-1 by the treatment with mild PAM. In order to elucidate the effects of mild PAM on the expression of HO-1, fibroblasts were treated with mild PAM for $6 \mathrm{~h}$. Mild PAM prepared by NTAPP irradiation for 1 or $2 \mathrm{~min}$ increased the expression of HO-1 mRNA (Fig. 2a). On the other hand, (mild) PAM prepared by irradiation for $3 \mathrm{~min}$ decreased HO- $1 \mathrm{mRNA}$ levels. The mild PAM treatment for $6 \mathrm{~h}$ maximally enhanced the expression of HO-1 mRNA (Fig. 2b). The protein level of HO-1 in mild PAM-treated cells also increased (Fig. 2c). HO-1 mRNA levels were significantly increased by the treatment with $50 \mu \mathrm{M} \mathrm{H}_{2} \mathrm{O}_{2}$-supplemented DMEM, but were only moderately increased by that with $10 \mu \mathrm{M} \mathrm{H}_{2} \mathrm{O}_{2}$-supplemented DMEM. HO- 1 mRNA levels were decreased by the treatment with $100 \mu \mathrm{M} \mathrm{H}_{2} \mathrm{O}_{2}$-supplemented DMEM (Fig. 2d). Mild PAM supplemented with catalase did not induce the expression of HO-1 mRNA, while $50 \mu \mathrm{M} \mathrm{H}_{2} \mathrm{O}_{2}$-supplemented DMEM achieved the similar up-regulation of HO-1 mRNA to mild PAM. tert-butylhydroquinone (tBHQ), a known HO-1 enhancer, up-regulated HO-1 mRNA (Fig. 2e, left). On the other hand, the mRNA of HO-2, a constitutive enzyme, was not induced by the treatment with mild PAM (Fig. 2e right). These results suggest that the ability of mild PAM to induce HO-1 depends on $\mathrm{H}_{2} \mathrm{O}_{2}$. In an attempt to clarify whether HO-1 induced by the mild PAM treatment confers cytoprotection against toxicity induced by a high dose of $\mathrm{H}_{2} \mathrm{O}_{2}$, fibroblasts were cultured in the presence of the HO-1 inhibitor $\mathrm{ZnPP}(10 \mu \mathrm{M})$ after a pretreatment with mild PAM. ZnPP eliminated the protective effects of mild PAM against $\mathrm{H}_{2} \mathrm{O}_{2}$-induced cell injury (Fig. 2f).

The treatment of A549 cells with mild PAM did not affect HO-1 mRNA levels (Fig. 1h right panel).

Enhancement of the ARE-binding activity of Nrf2 in mild PAM-treated fibroblasts. Nrf2 is a major transcription factor that binds to ARE in the promoter region of some antioxidative enzymes. When fibroblasts were treated with mild PAM for $6 \mathrm{~h}$, the nuclear translocation of Nrf2 was detected (Fig. 3a). This Nrf2 nuclear translocation was also observed by fluorescence imaging with a confocal microscopic analysis (Fig. 3b). In addition, ChIP assays showed an increase in Nrf2 binding to ARE in the HO-1 promoter (Fig. 3c). In order to elucidate whether Nrf2-mediated transcriptional activation is involved in the induction of HO-1 in response to mild PAM, we transfected Nrf2-specific siRNA (siNrf2) or control siRNA into fibroblasts and treated these cells with mild PAM for $6 \mathrm{~h}$. We confirmed that the transfection of siNrf2 caused a marked reduction in Nrf2 in fibroblasts (Fig. 3d). siNrf2 attenuated the induction of HO-1 mRNA by the treatment with mild PAM (Fig. 3e). Moreover, mild PAM-induced cytoprotection against toxicity induced by a high dose of $\mathrm{H}_{2} \mathrm{O}_{2}$ was significantly reduced by the transfection of siNrf2 (Fig. 3f).

\section{Discussion}

ROS and/or RNS or their derived species are generally considered to be the main bioactive components of PAM ${ }^{8-12}$. We previously reported that a PAM treatment effectively induced apoptosis in A549 lung adenocarcinoma cells ${ }^{25,27,28} \cdot \mathrm{H}_{2} \mathrm{O}_{2}$ and/or its derived $\bullet \mathrm{OH}$ disturb the mitochondrial-nuclear network in cells. PAM used in previous studies contained approximately 500 to $600 \mu \mathrm{M} \mathrm{H}_{2} \mathrm{O}_{2}$, a concentration that was about 10-fold higher than that in mild PAM used in this study. On the other hand, preconditioning effects of $\mathrm{H}_{2} \mathrm{O}_{2}$ have been reported in experiments with cultured cells $s^{32-34}$ and perfusion experiments using isolated rat hearts ${ }^{35}$. Low concentrations of $\mathrm{H}_{2} \mathrm{O}_{2}$, between approximately 10 to $100 \mu \mathrm{M}$, exerted effects in these studies ${ }^{31-33,35}$, whereas a high dose of $\mathrm{H}_{2} \mathrm{O}_{2}(500$ and $1000 \mu \mathrm{M})$ was used to induce strong oxidative stress ${ }^{34}$. As shown in Fig. 1, we observed preconditioning effects by mild PAM prepared using NTAPP irradiation for $2 \mathrm{~min}$, which contained approximately $50 \mu \mathrm{M} \mathrm{H}_{2} \mathrm{O}_{2}$, but not by PAM prepared using NTAPP irradiation for $1 \mathrm{~min}$ (containing approximately $10 \mu \mathrm{M} \mathrm{H}_{2} \mathrm{O}_{2}$ ). PAM prepared using NTAPP irradiation for 3 min (containing approximately $100 \mu \mathrm{M} \mathrm{H}_{2} \mathrm{O}_{2}$ ) showed cell toxicity. $\mathrm{H}_{2} \mathrm{O}_{2}$ needs to be the main active species in mild PAM for it to exert preconditioning effects because the addition of catalase to mild PAM eliminated these effects (Fig. 1e). The preconditioning effects of mild PAM depend on its $\mathrm{H}_{2} \mathrm{O}_{2}$ concentration and pretreatment time. We examined whether the pretreatment with $\mathrm{H}_{2} \mathrm{O}_{2}$ at a higher concentration ( 100 or $500 \mu \mathrm{M})$ for a shorter treatment time $(0.5$ to $3 \mathrm{~h})$ exerted preconditioning effects. However, the pretreatment with 
a
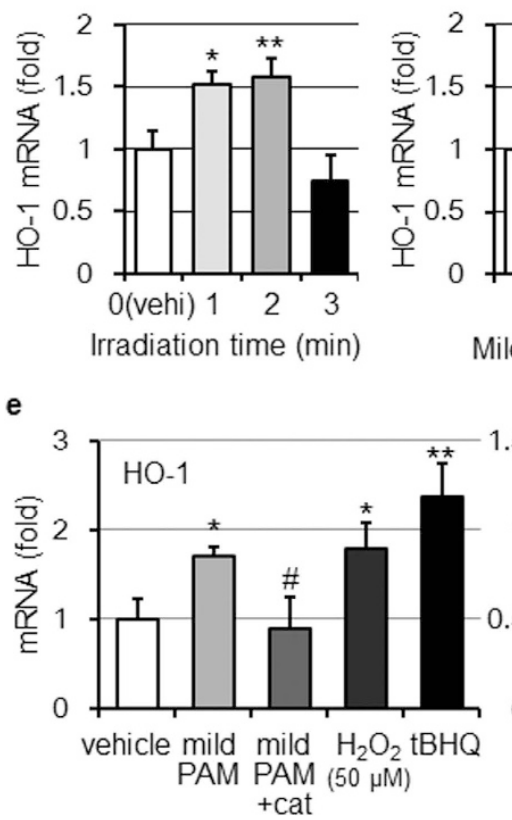

b

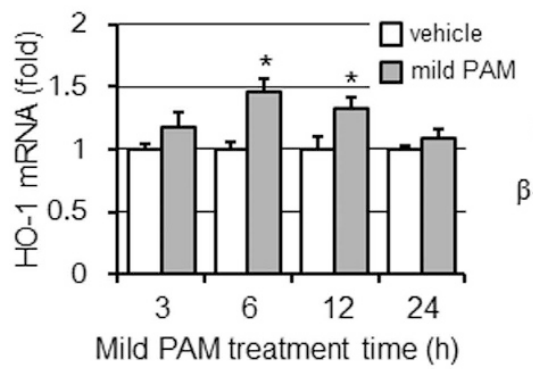

c

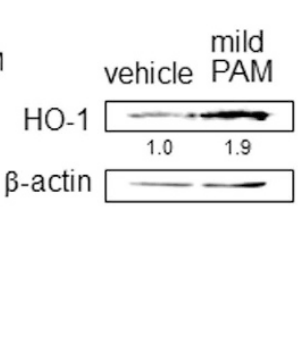

d

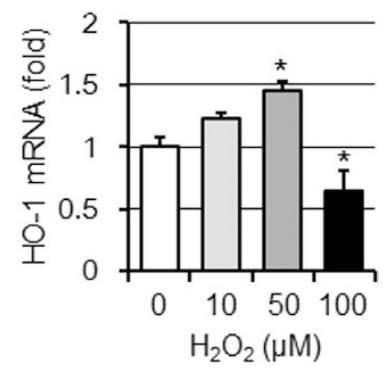

Figure 2. Mild PAM induced HO-1 expression. (a) Fibroblasts were treated with mild PAM prepared by the irradiation of NTAPP for the indicated times, and HO-1 mRNA levels were measured. Data are shown as the mean $\pm \mathrm{SD}(\mathrm{n}=3),{ }^{\star} p<0.05,{ }^{* *} p<0.01$ vs. vehicle. (b) Fibroblasts were treated with mild PAM or DMEM (vehicle) for the indicated times, and HO-1 mRNA levels were measured. Data are shown as the mean \pm SD $(\mathrm{n}=3),{ }^{\star} p<0.05$ vs. vehicle. (c) Fibroblasts were treated with mild PAM or DMEM (vehicle) for $6 \mathrm{~h}$ and then cultured in DMEM-10\%FCS for $18 \mathrm{~h}$ in a $\mathrm{CO}_{2}$ incubator. HO-1 protein levels were then measured by Western blotting. Values are fold changes from vehicle. (d) Fibroblasts were treated with the indicated concentration of $\mathrm{H}_{2} \mathrm{O}_{2}$ in DMEM for $6 \mathrm{~h}$, and HO- 1 mRNA levels were measured. Data are shown as the mean $\pm \mathrm{SD}(\mathrm{n}=3)$, ${ }^{*} p<0.05$ vs. vehicle. (e) Fibroblasts were treated with mild PAM in the presence or absence of catalase $(50 \mathrm{U} / \mathrm{ml})$, $50 \mu \mathrm{M} \mathrm{H}_{2} \mathrm{O}_{2}, 20 \mu \mathrm{M} \mathrm{tBHQ}$, or DMEM (vehicle) for $6 \mathrm{~h}$, and the mRNA levels of HO-1 (left) or HO-2 (right) were then measured. Data are shown as the mean $\pm \mathrm{SD}(\mathrm{n}=3),{ }^{*} p<0.05,{ }^{* *} p<0.01$ vs. vehicle, ${ }^{*} p<0.05$ vs. mild PAM only. (f) After the pretreatment with mild PAM or DMEM (vehicle) for $6 \mathrm{~h}$, fibroblasts were treated with DMEM$10 \%$ FCS for $18 \mathrm{~h}$ and then $500 \mu \mathrm{M} \mathrm{H}_{2} \mathrm{O}_{2}$ for $4 \mathrm{~h}$ in the presence or absence of $10 \mu \mathrm{M} \mathrm{ZnPP}$, followed by the LDH cytotoxic test. Control (Ct) fibroblasts were incubated with DMEM for $4 \mathrm{~h}$ instead of $500 \mu \mathrm{M} \mathrm{H}_{2} \mathrm{O}_{2}$ in DMEM. Data are shown as the mean $\pm \mathrm{SD}(\mathrm{n}=3),{ }^{* *} p<0.01$ vs. the control, ${ }^{\#} p<0.05,{ }^{\# \#} p<0.01$ vs. vehicle, ${ }^{\$ \$} p<0.01$.

mild PAM (about $50 \mu \mathrm{M} \mathrm{H}_{2} \mathrm{O}_{2}$ ) showed the safest and most reliable preconditioning effects (Fig. 1f). Mild PAM containing tens of $\mu \mathrm{M}$ of $\mathrm{H}_{2} \mathrm{O}_{2}$ may exert preconditioning effects; however, sensitivity to $\mathrm{H}_{2} \mathrm{O}_{2}$ differs among cells.

Nitrite, another main species in mild PAM, did not exert preconditioning effects (Fig. 1g). Nitrite by itself has been suggested to not play a role in the antitumor effects of $\mathrm{PAM}^{25,36}$. However, nitrite may affect the potency of PAM and mild PAM because the cancer cell-killing ability of $\mathrm{H}_{2} \mathrm{O}_{2}$ is reported to be synergistically enhanced by nitrite $^{36}$.

Nrf2-mediated HO-1 induction was previously shown to play crucial roles in the anti-oxidative defense system ${ }^{34-39}$. $\mathrm{HO}$ catalyzes the degradation of heme to carbon monoxide, a vasoactive gas; biliverdin, an antioxidant; and free iron ${ }^{40}$. The HO system possesses antioxidative and anti-apoptotic properties, and may influence cell proliferation, differentiation, and migration ${ }^{41}$. Therefore, we postulated that the Nrf2-HO system may be involved in mild PAM-induced preconditioning effects. Among the three $\mathrm{HO}$ isoforms (HO-1, $\mathrm{HO}-2$, and $\mathrm{HO}-3$ ), $\mathrm{HO}-1$ is the only inducible enzyme that plays a critical role in cytoprotection against oxidative stress, inflammation, and other noxious stimuli ${ }^{37}$. In the present study, mild PAM elevated HO-1 mRNA and protein levels, but not those of HO-2 mRNA (Fig. 2e). Moreover, $50 \mathrm{MM} \mathrm{H}_{2} \mathrm{O}_{2}$ significantly increased HO-1 mRNA levels (Fig. 2d). The induction of HO-1 mRNA was not observed when fibroblasts were treated with catalase-supplemented mild PAM (Fig. 2e, left). These results suggest that $\mathrm{H}_{2} \mathrm{O}_{2}$ in mild PAM is critical for the mild PAM-induced expression of HO- 1 . However, we cannot rule out the possibility that a mechanism other than the induction of HO- 1 is involved in the preconditioning effects of the mild PAM pretreatment, and other unknown species in mild PAM may play a role in the induction of HO- 1 because mild PAM prepared using NTAPP irradiation for 1 min increased HO-1 mRNA levels, but did not affect cell injury (Fig. 1b), and the induction of HO-1 by $10 \mu \mathrm{M} \mathrm{H}_{2} \mathrm{O}_{2}$ was moderate (Fig. 2d). The roles of HO-2 and HO-3 in cells currently remain unclear. HO-2 mRNA levels are low in human dermal fibroblasts, but high in keratinocytes, and HO-2 in keratinocytes plays a role in maintaining iron release from ferritin ${ }^{42}$. The result that mild PAM did not exert preconditioning effects in A549 cells was attributed to the absence of an increase in HO-1 mRNA levels (Fig. 1h); however, the underlying mechanisms remain unclear. 
a

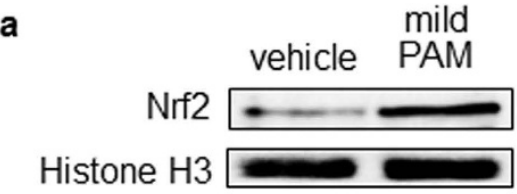

b
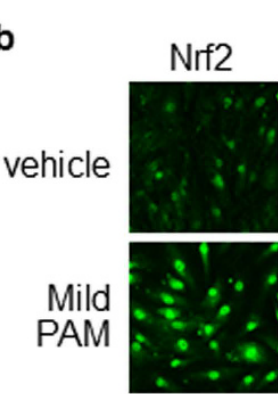

$\mathrm{tBHQ}$

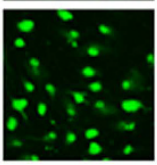

Hoechst
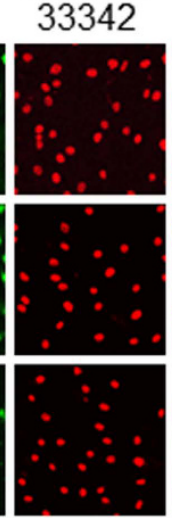

c

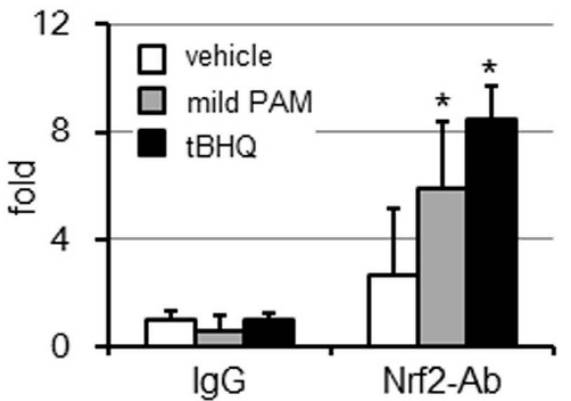

d

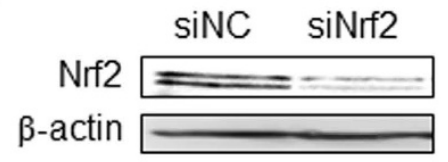

e

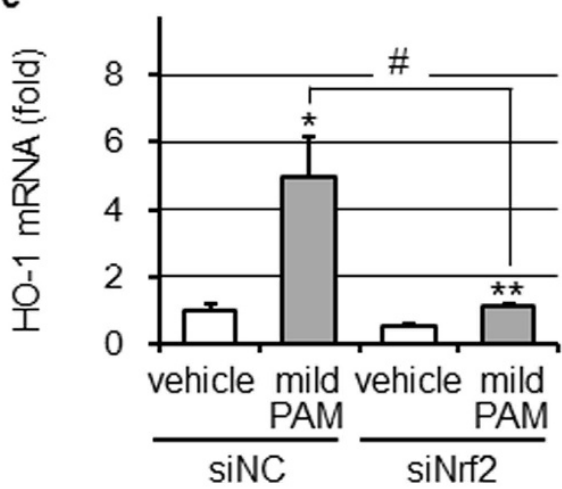

f

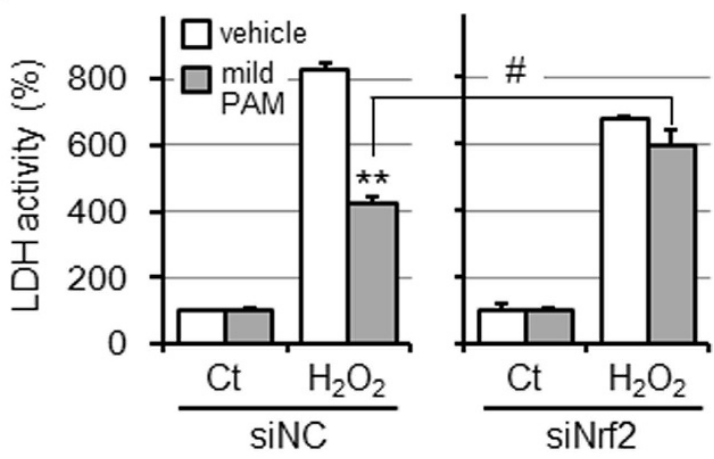

Figure 3. Mild PAM enhanced Nrf2 signaling. (a) Fibroblasts were treated with mild PAM or DMEM (vehicle) for $6 \mathrm{~h}$ and their nuclear fractions were then isolated and subjected to Western blotting for Nrf2. (b) The nuclear translocation of $\mathrm{Nrf} 2$ was assessed by immunofluorescence staining. Fibroblasts were treated with mild PAM, tBHQ $(20 \mu \mathrm{M})$, or DMEM (vehicle) for $6 \mathrm{~h}$. Cells were fixed and labeled with an anti-Nrf2 antibody, as described in the Materials and methods. Cell nuclei were labeled with Hoechst 33342 . Scale bar, $50 \mu \mathrm{m}$. (c) The ARE binding activity of Nrf2 was measured using the ChIP assay. Fibroblasts were treated with mild PAM, tBHQ $(20 \mu \mathrm{M})$, or DMEM (vehicle) for $6 \mathrm{~h}$. Their chromatins were cross-linked and immunoprecipitated with IgG or an anti-Nrf2 antibody (Ab), and DNAs were amplified using an ARE-specific primer. Data are shown as the mean $\pm \mathrm{SD}(\mathrm{n}=3),{ }^{*} p<0.05$ vs. vehicle. (d) After siNrf2 and the siNC were transfected into fibroblasts for $24 \mathrm{~h}$ in a $\mathrm{CO}_{2}$ incubator, whole cell extracts were prepared and followed by Western blotting for Nrf2. (e) After transfection of siNrf2 or siNC, cells were treated with mild PAM or DMEM (vehicle) for $6 \mathrm{~h}$ and HO-1 mRNA levels were then measured. Data are shown as the mean $\pm \mathrm{SD}(\mathrm{n}=3)$, ${ }^{\star} p<0.05,{ }^{* *} p<0.01$ vs. vehicle, ${ }^{\sharp} p<0.05$. (f) After transfection of siNrf2 or siNC, cells were treated with mild PAM or DMEM (vehicle) for $6 \mathrm{~h}$, followed by cultivation for $18 \mathrm{~h}$, a treatment with or without $500 \mu \mathrm{M} \mathrm{H}_{2} \mathrm{O}_{2}$ for $4 \mathrm{~h}$, and the LDH assay. Control (Ct) fibroblasts were incubated with DMEM for $4 \mathrm{~h}$ instead of $500 \mu \mathrm{M} \mathrm{H}_{2} \mathrm{O}_{2}$ in DMEM. Data are shown as the mean \pm SD $(\mathrm{n}=3),{ }^{* *} p<0.01$ vs. vehicle, ${ }^{*} p<0.05$.

HO-1 is positively regulated by the Keap1-Nrf2-ARE pathway ${ }^{39,40,43}$. In this study, we revealed the nuclear translocation (Fig. 3a and b) and recruitment of Nrf2 to $\mathrm{HO}-1$ promoters (Fig. 3c) in fibroblasts exposed to mild PAM for $6 \mathrm{~h}$. The knockdown of Nrf2 attenuated the induction of HO-1 by mild PAM (Fig. 3e), suggesting that mild PAM up-regulates the Nrf2-dependent expression of HO-1. The up-regulation of HO-1 correlated with mild PAM-induced preconditioning effects against a high dose of $\mathrm{H}_{2} \mathrm{O}_{2}$ (Figs 1 and 2). Our results showed that the addition of ZnPP, a HO-1 specific inhibitor (Fig. 2f) or knockdown of Nrf2 (Fig. 3f) completely abrogated the preconditioning effects of mild PAM. $\mathrm{H}_{2} \mathrm{O}_{2}$-induced Keap1-Nrf2-ARE signaling pathway is well known ${ }^{18-20}$. In this pathway, $\mathrm{H}_{2} \mathrm{O}_{2}$ oxidize cysteine residues in Keap1 and change its conformation ${ }^{18,44}$. This conformational change weakens the interaction between Keap1 and Nrf2, and inhibits the subsequent ubiquitination and degradation of Nrf2. Therefore, Nrf2 is stabilized and translocated to the nucleus, and then binds to ARE in the HO-1 promoter. The phosphatidylinositol 3 kinase (PI3K)-Akt signaling pathway is known to activate $\mathrm{Nrf} 2^{33,45,46}$ and its downstream signaling induces HO- $1^{45} \cdot \mathrm{H}_{2} \mathrm{O}_{2}$ has been identified as an activator of the PI3K-Akt signaling pathway ${ }^{46}$. 


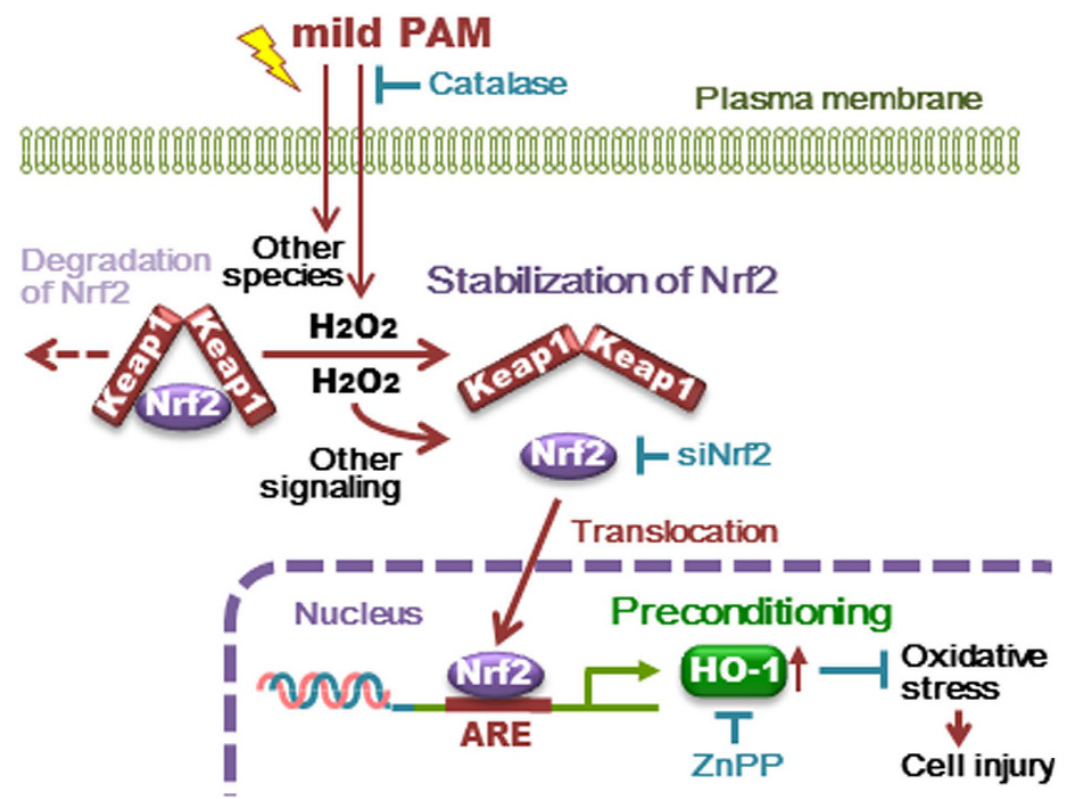

Figure 4. Cytoprotective effects of mild PAM against oxidative stress in human skin fibroblasts. Mild PAM protects fibroblasts from oxidative stress through the up-regulation of HO-1 mediated by the Nrf2-ARE pathway.

ROS/RNS or their derived species are generally considered to be the main bioactive species in PAM. We speculated the involvement of other $\mathrm{H}_{2} \mathrm{O}_{2}$-cooperating species in PAM-induced apoptosis in cancer cells, whereas $\mathrm{H}_{2} \mathrm{O}_{2}$ needs to be the main active species in the reaction ${ }^{25}$. Moreover, ROS-derived amino acid peroxides (organic peroxides) ${ }^{1}$ and/or nitrites ${ }^{36}$ may contribute to the potency of PAM. It is not currently possible to rule out the involvement of these species and other unknown species and latent mechanisms in the preconditioning effects of mild PAM.

A relatively low dose of plasma has been reported to induce the proliferation of cells ${ }^{7,8}$, and has potential for clinical applications, for example, wound healing ${ }^{2,47,48}$. On the other hand, the induction of HO-1 has also been reported to play a crucial role in wound healing ${ }^{41,49,50}$. Our results clearly demonstrate that the pretreatment with mild PAM protected fibroblasts from oxidative stress by up-regulating $\mathrm{HO}$-1; tens of $\mu \mathrm{M}$ of $\mathrm{H}_{2} \mathrm{O}_{2}$ in mild PAM contribute to preconditioning effects; the $\mathrm{H}_{2} \mathrm{O}_{2}$-induced activation of the Nrf2-ARE signaling pathway needs to be involved in the up-regulation of HO-1 (Fig. 4). Although further investigations are needed, the results of the present study provide evidence for the anti-oxidative stress functions of mild PAM and its potential for clinical applications.

\section{Materials and Methods}

Cell culture. Human skin fibroblasts were grown in Dulbecco's modified Eagle's medium (DMEM, Nissui Pharmaceutical Co., Tokyo, Japan) supplemented with $10 \%$ fetal calf serum (FCS), 100 units/mL penicillin, and $100 \mu \mathrm{g} / \mathrm{ml}$ streptomycin (DMEM-10\%FCS) under an atmosphere of $5 \% \mathrm{CO}_{2} / 95 \%$ air at $37^{\circ} \mathrm{C}$.

Preparation of mild PAM. The experimental set-up of the NTAPP irradiation system used in this study consisted of a power controller/gas flow regulator, argon gas cylinder, and NTAPP source head (PN-120 TPG, NU Global, Nagoya, Japan) and was the same as the system described previously ${ }^{25-28}$. The flow rate of argon gas was set at 2 standard liters/min. Mild PAM was prepared by exposing NTAPP to $4 \mathrm{ml}$ of DMEM (Sigma 5796), without FCS and antibiotics, in 60-mm culture dishes (Nunc 150288). The distance between the plasma source and surface of the medium was fixed at $\mathrm{L}=4 \mathrm{~mm}$. The duration time for PAM irradiation was $2 \mathrm{~min}$, except in the time-course experiment.

Assays to measure $\mathrm{H}_{2} \mathrm{O}_{2}$ and nitrite concentrations. $\mathrm{H}_{2} \mathrm{O}_{2}$ concentrations in mild PAM were assayed by a colorimetric method using 3-methyl-2-benzothiazolinone hydrazine hydrochloride, $N, N$-dimethylaniline, and horseradish peroxidase ${ }^{25}$. Nitrite as NOx was assayed by the Griss method ${ }^{51}$. The concentrations of $\mathrm{H}_{2} \mathrm{O}_{2}$ and nitrite in mild PAM were measured immediately after its preparation and it was promptly used in experiments.

Cytotoxicity assay. The lactate dehydrogenase (LDH) assay was used to estimate cytotoxicity. Fibroblasts were seeded at $1.5 \times 10^{4}$ cells/well in a 96-well microplate (Nunc 167008), cultured for $24 \mathrm{~h}$ in a $\mathrm{CO}_{2}$ incubator, and then used in experiments. Cells were treated with $80 \mu \mathrm{l}$ of mild PAM for $6 \mathrm{~h}$ in a $\mathrm{CO}_{2}$ incubator. After the removal of mild PAM, cells were provided DMEM-10\% FCS $(80 \mu \mathrm{l})$ and incubated for $18 \mathrm{~h}$ in a $\mathrm{CO}_{2}$ incubator. After the removal of medium, cells were treated with $500 \mu \mathrm{M} \mathrm{H}_{2} \mathrm{O}_{2}$ in DMEM $(80 \mu \mathrm{l})$ as an oxidative stress for $4 \mathrm{~h}$ in a $\mathrm{CO}_{2}$ incubator, and this was followed by an assay for LDH released into conditioned medium using a LDH cytotoxic test (Wako Pure Chemical, Osaka, Japan) according to the manufacturer's directions. 
Reverse transcriptional-polymerase chain reaction (RT-PCR) analysis. Fibroblasts were cultured in 60 -mm culture dishes (seeded at $4 \times 10^{5}$ cells $/$ dish) for $24 \mathrm{~h}$ in a $\mathrm{CO}_{2}$ incubator and then used in experiments. After the treatment with mild PAM $(3 \mathrm{ml})$ for $6 \mathrm{~h}$, cells were washed with cold phosphate-buffered saline (PBS) and total RNA was extracted from cells with TRIzol reagent (Invitrogen, Carlsbad, CA, USA). First-strand cDNA was generated from $1 \mu \mathrm{g}$ of total RNA. RT-PCR was performed with specific primers described below and $\mathrm{rTaq}$ (Toyobo, Ootsu, Japan) according to the manufacturer's directions. The primer sequences used in this study were as follows: HO-1, sense 5'-CCA GAA GAG CTG CAC CGC AA-3' , antisense $5^{\prime}$-GCT GGA TGT TGA GCA GGA AC-3'; HO-2, sense 5'-GAA GGA GCT GTT TAA GCT GG-3', antisense 5'-GGG AGT TTC AGT GCT CGC TG-3'. Aliquots of PCR products were loaded on a $2 \%(\mathrm{w} / \mathrm{v})$ agarose gel for electrophoresis, and a densitometric analysis of the PCR products was performed with Multi Gauge V3.0 (Fuji Film, Tokyo, Japan).

Real-time RT-PCR was performed using Thunderbird ${ }^{\mathrm{TM}}$ SYBR qPCR Mix (Toyobo) according to the manufacturer's protocol. The primers used for HO-1 were same as those described above.

Western blotting. Fibroblasts were cultured in $60-\mathrm{mm}$ culture dishes (seeded at $4 \times 10^{5}$ cells/dish) for $24 \mathrm{~h}$ in a $\mathrm{CO}_{2}$ incubator and then used in experiments. After the treatment with mild PAM $(3 \mathrm{ml})$ for $6 \mathrm{~h}$ in a $\mathrm{CO}_{2}$ incubator, cells were washed with cold PBS, scraped, and lysed in $50 \mu \mathrm{l}$ of lysis buffer $(20 \mathrm{mM}$ Tris- $\mathrm{HCl}, \mathrm{pH} 7.4$, containing $1 \mathrm{mM}$ EDTA, $1 \mathrm{mM}$ EGTA, $10 \mathrm{mM} \mathrm{NaF}, 1 \mathrm{mM} \mathrm{Na}_{3} \mathrm{VO}_{4}, 20 \mathrm{mM} \beta$-glycerophosphate, $1 \mathrm{mM}$ phenylmethylsulfonyl fluoride (PMSF), $1 \mathrm{mM}$ dithiothreitol (DTT), $2 \mu \mathrm{g} / \mathrm{ml}$ leupeptin, and $1 \%$ Triton X-100), followed by centrifugation at $17,000 \times g$ for $5 \mathrm{~min}$. After centrifugation, the protein concentration of the supernatant was assayed using a Bio-Rad protein assay reagent. Extracts containing $20 \mu \mathrm{g}$ protein were boiled with sample buffer (62.5 mM Tris- $\mathrm{HCl}, \mathrm{pH} 6.8$, containing $2 \%$ sodium dodecylsulfate (SDS), $10 \%$ glycerol, $50 \mathrm{mM} \mathrm{DTT}$, and $0.01 \%$ bromophenol blue) for $5 \mathrm{~min}$ and separated by SDS-PAGE on $15 \%(\mathrm{w} / \mathrm{v})$ polyacrylamide gels. After being transferred electrophoretically onto PVDF membranes, non-specific binding sites were blocked with PBS containing $1 \%$ bovine serum albumin (BSA). Membranes were subsequently incubated with an anti-HO- 1 antibody (1:1,000, Cell Signaling Technology, Danvers, MA, USA) or anti- $\beta$-actin antibody (1:1,000, Merck Millipore, Billerica, MA, USA). After the membranes had been washed three times with PBST (PBS containing $0.1 \%$ Tween 20 ), the blots were incubated with biotin-conjugated goat anti-rabbit or -mouse antibody (1:1,000, Zymed Laboratories, South San Francisco, CA, USA), followed by an incubation with ABC reagents (1:5,000, Vector Laboratories, Burlingame, CA, USA). Bands were detected using ImmunoStar LD (Wako Pure Chemical), and imaged using an LAS-3000 UV mini (Fuji Film).

Regarding nuclear extraction, fibroblasts were collected and lysed in $800 \mu$ l of lysis buffer A ( $20 \mathrm{mM}$ HEPES- $\mathrm{NaOH}, \mathrm{pH} 7.8$, containing $15 \mathrm{mM} \mathrm{KCl}, 2 \mathrm{mM} \mathrm{MgCl}_{2}, 2 \mathrm{mM}$ DTT, $0.5 \mathrm{mM}$ PMSF, and $10 \mu \mathrm{g} / \mathrm{ml}$ leupeptin) followed by centrifugation at $830 \times g$ for $30 \mathrm{sec}$. The pellets were suspended in $150 \mu$ l of lysis buffer B (lysis buffer A containing $0.5 \%$ Nonidet P-40 (NP-40)) and incubated for $30 \mathrm{~min}$ on ice. After centrifugation at $9,000 \times g$ for $30 \mathrm{sec}$, the pellets were suspended in $40 \mu \mathrm{l}$ of lysis buffer C $(20 \mathrm{mM}$ HEPES- $\mathrm{NaOH}, \mathrm{pH} 7.8$, containing $0.4 \mathrm{M}$ $\mathrm{NaCl}, 2 \mathrm{mM}$ DTT, $0.5 \mathrm{mM}$ PMSF, and $10 \mu \mathrm{g} / \mathrm{ml}$ leupeptin). After centrifugation at 20,000 $\times \mathrm{g}$ for $20 \mathrm{~min}$, the supernatant was saved as the nuclear fraction. The protein concentration of the supernatant was assayed using a Bio-Rad protein assay reagent. Extracts containing $20 \mu \mathrm{g}$ protein were boiled with sample buffer for $5 \mathrm{~min}$ and separated by SDS-PAGE on $12 \%(\mathrm{w} / \mathrm{v})$ polyacrylamide gels. After being transferred electrophoretically onto PVDF membranes, non-specific binding sites were blocked with PBS containing 1\% BSA. Membranes were subsequently incubated with an anti-Nrf2 rabbit polyclonal antibody (1:1,000, Santa Cruz Biotechnology, Santa Cruz, CA, USA) or anti-histone H3 rabbit monoclonal antibody (1:1,000, Cell Signaling Technology). After the membranes had been washed three times with PBST, blots were incubated with a biotin-conjugated goat anti-rabbit or -mouse antibody $(1: 1,000)$, followed by an incubation with $\mathrm{ABC}$ reagents $(1: 5,000)$. Bands were detected using ImmunoStar LD, and imaged using an LAS-3000 UV mini.

Fluorescence imaging for Nrf2. Fibroblasts $\left(6 \times 10^{4}\right.$ cells $)$ were seeded on collagen-coated coverslips ( $12 \mathrm{~mm}$ in diameter) in a 4-well culture plate (Nunc 176740) and cultured for $24 \mathrm{~h}$ in a $\mathrm{CO}_{2}$ incubator. After the treatment with mild PAM $(500 \mu \mathrm{l})$ for $6 \mathrm{~h}$ in a $\mathrm{CO}_{2}$ incubator, cells were washed with PBS followed by fixation with $3 \%$ paraformaldehyde, permeabilization with $0.1 \%$ Triton X-100, and blocking with $3 \%$ BSA solution. Cells were then incubated for $1 \mathrm{~h}$ with an anti-Nrf2 antibody (1:50) diluted with Can Get Signal Immunostain solution (Toyobo), followed by an incubation for $1 \mathrm{~h}$ with Alexa Fluor 488 goat anti-rabbit IgG (1:400). After the labeling of cell nuclei with Hoechst 33342 (1:1,000, Dojindo, Kumamoto, Japan), cells were washed and visualized under the LSM710 confocal laser fluorescence microscope (Carl Zeiss, Gottingen, Germany).

Chromatin Immunoprecipitation (ChIP) Assay. Fibroblasts seeded at $1 \times 10^{6}$ cells/dish in a 90-mm culture dish (Nunc 150350) were cultured for $24 \mathrm{~h}$ in a $\mathrm{CO}_{2}$ incubator. After the cells had been treated with mild PAM $(10 \mathrm{ml})$ for $6 \mathrm{~h}$ in a $\mathrm{CO}_{2}$ incubator, protein-DNA complexes were cross-linked using $1 \%$ formaldehyde in DMEM$10 \%$ FCS at room temperature for $5 \mathrm{~min}$. The reagent was subsequently quenched by the addition of $200 \mathrm{mM}$ glycine in DMEM at room temperature for $5 \mathrm{~min}$. Cells were washed with PBS, and then scraped and lysed in $1 \mathrm{ml}$ of NP-40 buffer ( $10 \mathrm{mM}$ Tris- $\mathrm{HCl}, \mathrm{pH} 8.0$, containing $10 \mathrm{mM} \mathrm{NaCl}$ and $0.5 \% \mathrm{NP}-40)$, and centrifuged at $830 \times g$ for $3 \mathrm{~min}$. The pellet was dissolved in $100 \mu \mathrm{l}$ of SDS buffer $(50 \mathrm{mM}$ Tris- $\mathrm{HCl}, \mathrm{pH} 8.0$, containing $1 \%$ SDS and $10 \mathrm{mM}$ EDTA), and added to $400 \mu \mathrm{l}$ of ChIP dilution buffer ( $50 \mathrm{mM}$ Tris- $\mathrm{HCl}, \mathrm{pH} 8.0$, containing $167 \mathrm{mM}$ $\mathrm{NaCl}, 1.1 \%$ Triton X-100, 0.11\% deoxycholic acid, $10 \mathrm{mM} \mathrm{NaF}, 1 \mathrm{mM} \mathrm{Na}_{3} \mathrm{VO}_{4}, 20 \mathrm{mM} \beta$-glycerophosphate, $1 \mathrm{mM}$ DTT, and $1 \mathrm{mM}$ PMSF). Genomic DNA was sheared using an ultrasonic homogenizer Vivracell VC100 (Sonic \& Materials, Danbury, CT, USA) to achieve an estimated DNA size range of 150 to $800 \mathrm{bp}$, and $500 \mu \mathrm{l}$ of ChIP dilution buffer was then added. One hundred microliters of sheared genomic DNA was diluted with $400 \mu \mathrm{l}$ of RIPA buffer I ( $50 \mathrm{mM}$ Tris- $\mathrm{HCl}$, pH 8.0, containing $150 \mathrm{mM} \mathrm{NaCl}, 1 \mathrm{mM}$ EDTA, $0.1 \%$ SDS, $0.1 \%$ deoxycholic acid, and proteinase inhibitors) and incubated with a rabbit anti-Nrf2 antibody $(1: 100)$ at $4{ }^{\circ} \mathrm{C}$ overnight with shaking. The 
solution was subsequently incubated with $20 \mu \mathrm{l}$ of Dynabeads Protein $\mathrm{G}$ (Invitrogen) at $4{ }^{\circ} \mathrm{C}$ for $2 \mathrm{~h}$ with shaking. After being incubated, the beads were sequentially washed with RIPA buffer I, RIPA buffer II (50 mM Tris-HCl, pH 8.0, containing $500 \mathrm{mM} \mathrm{NaCl}, 1 \mathrm{mM}$ EDTA, $0.1 \%$ SDS, $0.1 \%$ deoxycholic acid, and proteinase inhibitors), and TE buffer ( $10 \mathrm{mM}$ Tris-HCl, $\mathrm{pH} 8.0$, containing $1 \mathrm{mM}$ EDTA). The beads were suspended in $100 \mu \mathrm{l}$ of ChIP elution buffer (10 mM Tris-HCl, pH 8.0, containing $300 \mathrm{mM} \mathrm{NaCl}, 5 \mathrm{mM}$ EDTA, and $0.5 \%$ SDS) with $1 \mu \mathrm{l}$ Rase (Roche Diagnostics, Mannheim, Germany) and incubated at $37^{\circ} \mathrm{C}$ for $30 \mathrm{~min}$, followed by the addition of $1 \mu \mathrm{l}$ proteinase $\mathrm{K}$ (Roche Diagnostics) and an incubation at $65^{\circ} \mathrm{C}$ for $2 \mathrm{~h}$. After phenol-chloroform extraction and ethanol precipitation, genomic DNA was dissolved in $20 \mu \mathrm{l}$ of TE buffer. The abundance of ARE in ChIP precipitates was quantified using a RT-PCR analysis. The primer sequences for ARE were sense $5^{\prime}$-CCC TGC TGA GTA ATC CTT TCC CGA-3', antisense 5'-ATG TCC CGA CTC CAG ACT CCA-3'.

RNA interference study. Nrf2-specific short interfering RNA (siRNA) and scramble control siRNA were obtained from Life Technologies Japan (Tokyo, Japan). Transfection was performed using Lipofectamine RNAiMAX Reagent (Thermo Fischer Scientific, Yokohama, Japan), according to the manufacturer's protocol with Nrf2-specific siRNA AM16708; human NFE2L2; target sequences including sense 5'-CCU UAU AUC UCG AAG UUU Utt-3'; antisense 5'-AAA ACU UCG AGA UAU AAG Gtg- ${ }^{\prime}$. Briefly, cells were transfected with $50 \mathrm{nmol} / 1$ siRNAs directed against Nrf2 (siNrf2) or negative control siRNA (siNC) and then cultured for $24 \mathrm{~h}$ in a $\mathrm{CO}_{2}$ incubator, followed by assays for HO-1 mRNA levels and cytoprotective ability.

Data analysis. Data are presented as the mean \pm SD of three experiments. Data were analyzed by Welch's $t$-test. A $p$ value of less than 0.05 was considered significant.

\section{References}

1. Kalghatgi, S. et al. Effects of non-thermal plasma on mammalian cells. PLoS One 6, e16270 (2011).

2. Haertel, B., von Woedtke, T., Weltmann, K. D. \& Lindequist, U. Non-thermal atmospheric-pressure plasma possible application in wound healing. Biomol. Ther. 22, 477-490 (2014).

3. Ke, Z. \& Huang, Q. Haem-assisted dityrosine-cross-linking of fibrinogen under non-thermal plasma exposure: one important mechanism of facilitated blood coagulation. Sci. Rep. 6, 26982 (2016).

4. Sung, S. J. et al. Sterilization effect of atmospheric pressure non-thermal air plasma on dental instruments. J. Adv. Prosthodont. 5, 2-8 (2013).

5. Zhunussova, A. et al. Mitochondria-mediated anticancer effects of non-thermal atmospheric plasma. PLoS One 11, e0156818 (2016).

6. Tanaka, H. et al. Plasma-activated medium selectively kills glioblastoma brain tumor cells by down-regulating a survival signaling molecule, AKT kinase. Plasma Med. 1, 265-277 (2011)

7. Kalghatgi, S., Friedman, G., Fridman, A. \& Clyne, A. M. Endothelial cell proliferation is enhanced by low dose non-thermal plasma through fibroblast growth factor-2 release. Ann. Biomed. Eng. 38, 748-757 (2010).

8. Vandamme, M. et al. ROS implication in a new antitumor strategy based on non-thermal plasma. Int. J. Cancer 130, 2185-2194 (2012).

9. Panngom, K. et al. Preferential killing of human lung cancer cell lines with mitochondrial dysfunction by nonthermal dielectric barrier discharge plasma. Cell Death Dis. 4, e642 (2013).

10. Ahn, H. J. et al. Targeting cancer cells with reactive oxygen and nitrogen species generated by atmospheric-pressure air plasma. PLoS One 9, e86173 (2014).

11. Lee, Y. et al. Atmospheric-pressure plasma jet induces DNA double-strand breaks that require a Rad51-mediated homologous recombination for repair in Saccharomyces cerevisiae. Arch. Biochem. Biophys. 560, 1-9 (2014).

12. Okazaki, Y. et al. Direct exposure of non-equilibrium atmospheric pressure plasma confers simultaneous oxidative and ultraviolet modifications in biomolecules. J. Clin. Biochem. Nutr. 55, 207-215 (2014).

13. Zhang, J. et al. ROS and ROS-mediated cellular signaling. Oxid. Med. Cell. Longev. 2016, 4350965 (2016).

14. Kim, J. \& Keum, Y. S. NRF2, a key regulator of antioxidants with two faces towards cancer. Oxid. Med. Cell. Longev. 2016, 2746457 (2016).

15. Kobayashi, A. et al. Oxidative and electrophilic stresses activate Nrf2 through inhibition of ubiquitination activity of Keap1. Mol. Cell. Biol. 26, 221-229 (2006).

16. Ashino, T., Yamamoto, M. \& Numazawa, S. Nrf2/Keap1 system regulates vascular smooth muscle cell apoptosis for vascular homeostasis: role in neointimal formation after vascular injury. Sci. Rep. 6, 26291 (2016).

17. Itoh, K., Ye, P., Matsumiya, T., Tanji, K. \& Ozaki, T. Emerging functional cross-talk between the Keap1-Nrf2 system and mitochondria. J. Clin. Biochem. Nutr. 56, 91-97 (2015).

18. Fourquet, S., Guerois, R., Biard, D. \& Toledano, M. B. Activation of NRF2 by nitrosative agents and $\mathrm{H}_{2} \mathrm{O}_{2}$ involves KEAP1 disulfide formation. J. Biol. Chem. 285, 8463-8471 (2010).

19. Umemura, K. et al. Preconditioning by sesquiterpene lactone enhances $\mathrm{H}_{2} \mathrm{O}_{2}$-induced Nrf2/ARE activation. Biochem. Biophys. Res. Commun. 368, 948-954 (2008).

20. Jian, Z. et al. Heme oxygenase-1 protects human melanocytes from $\mathrm{H}_{2} \mathrm{O}_{2}$-induced oxidative stress via the Nrf2-ARE pathway. J. Invest. Dermatol. 131, 1420-1427 (2011).

21. Naïtali, M., Kamgang-Youbi, G., Herry, J. M., Bellon-Fontaine, M. N. \& Brisset, J. L. Combined effects of long-living chemical species during microbial inactivation using atmospheric plasma-treated water. Appl. Environ. Microbiol. 76, 7662-7664 (2010).

22. Utsumi, F. et al. Effect of indirect nonequilibrium atmospheric pressure plasma on anti-proliferative activity against chronic chemoresistant ovarian cancer cells in vitro and in vivo. PLoS One 8, e81576 (2013).

23. Hoentsch, M., von Woedtke, T., Weltmann, K.-D. \& Nebe, J. B. Time-dependent effects of low-temperature atmospheric-pressure argon plasma on epithelial cell attachment, viability and tight junction formation in vitro. J. Phys. D: Appl. Phys. 45, 025206 (2012).

24. Shimizu, T., Iwafuchi, Y., Morfill, G. E. \& Sato, T. Formation of thermal flow fields and chemical transport in air and water by atmospheric plasma. New J. Phys. 13, 053025 (2011).

25. Adachi, T. et al. Plasma-activated medium induced A549 cell injury by a spiral apoptotic cascade involving the mitochondrialnuclear network. Free Radic. Biol. Med. 79, 28-44 (2015).

26. Hara, H., Taniguchi, M., Kobayashi, M., Kamiya, T. \& Adachi, T. Plasma-activated medium-induced intracellular zinc liberation causes death of SH-SY5Y cells. Arch. Biochem. Biophys. 584, 51-60 (2015).

27. Adachi, T. et al. Iron stimulates plasma-activated medium-induced A549 cell injury. Sci. Rep. 6, 20928 (2016).

28. Adachi, T., Kano, A., Nonomura, S., Kamiya, T. \& Hara, H. Histone deacetylase inhibitors stimulate the susceptibility of A549 cells to a plasma-activated medium treatment. Arch. Biochem. Biophys. 606, 120-127 (2016). 
29. Saito, K. et al. Tumor-selective mitochondrial network collapse induced by atmospheric gas plasma-activated medium. Oncotarget 7, 19910-19927 (2016).

30. Utsumi, F. et al. Variable susceptibility of ovarian cancer cells to non-thermal plasma-activated medium. Oncol. Rep. 35, 3169-3177 (2016).

31. Schmidt, A. et al. Non-thermal plasma activates human keratinocytes by stimulation of antioxidant and phase II pathways. J. Biol. Chem. 290, 6731-6750 (2015).

32. Bell, K. F. et al. Mild oxidative stress activates Nrf2 in astrocytes, which contributes to neuroprotective ischemic preconditioning. Proc. Natl. Acad. Sci. USA 108, E1-2 (2011).

33. Angeloni, C. et al. $\mathrm{H}_{2} \mathrm{O}_{2}$ preconditioning modulates phase II enzymes through $\mathrm{p} 38$ MAPK and PI3K/Akt activation. Am. J. Physiol. Heart Circ. Physiol. 300, H2196-2205 (2011).

34. Bosutti, A. \& Degens, H. The impact of resveratrol and hydrogen peroxide on muscle cell plasticity shows a dose-dependent interaction. Sci. Rep. 5, 8093 (2015).

35. Wang, Z. H., Liu, J. L., Wu, L., Yu, Z. \& Yang, H. T. Concentration-dependent wrestling between detrimental and protective effects of $\mathrm{H}_{2} \mathrm{O}_{2}$ during myocardial ischemia/reperfusion. Cell Death Dis. 5, e1297 (2014).

36. Kurake, N. et al. Cell survival of glioblastoma grown in medium containing hydrogen peroxide and/or nitrite, or in plasma-activated medium. Arch. Biochem. Biophys. 605, 102-108 (2016).

37. Park, S. A., Lee, M. H., Na, H. K. \& Surh, Y. J. 4-Hydroxyestradiol induces mammary epithelial cell transformation through Nrf2mediated heme oxygenase-1 overexpression. Oncotarget. doi: 10.18632/oncotarget.10516 (2016).

38. Hara, H., Ohta, M. \& Adachi, T. Apomorphine protects against 6-hydroxydopamine-induced neuronal cell death through activation of the Nrf2-ARE pathway. J. Neurosci. Res. 84, 860-866 (2006).

39. Biswas, C. et al. Nuclear heme oxygenase-1 (HO-1) modulates subcellular distribution and activation of Nrf2, impacting metabolic and anti-oxidant defenses. J. Biol. Chem. 289, 26882-26894 (2014).

40. Cai, C. et al. The heme oxygenase 1 inducer (CoPP) protects human cardiac stem cells against apoptosis through activation of the extracellular signal-regulated kinase (ERK)/NRF2 signaling pathway and cytokine release. J. Biol. Chem. 287, 33720-33732 (2012).

41. Chen, Q. Y. et al. Heme oxygenase-1 promotes delayed wound healing in diabetic rats. J. Diabetes Res. 2016, 9726503 (2016).

42. Applegate, L. A., Noël, A., Vile, G., Frenk, E. \& Tyrrell, R. M. Two genes contribute to different extents to the heme oxygenase enzyme activity measured in cultured human skin fibroblasts and keratinocytes: implications for protection against oxidant stress. Photochem. Photobiol. 61, 285-291 (1995).

43. Lee, D. S. \& Jeong, G. S. Butein provides neuroprotective and anti-neuroinflammatory effects through Nrf2/ARE-dependent HO-1 expression by activating the PI3K/AKT pathway. Br. J. Pharmacol. 173, 2894-2909 (2016).

44. Marinho, H. S., Real, C., Cyrne, L., Soares, H. \& Antunes, F. Hydrogen peroxide sensing, signaling and regulation of transcription factors. Redox Biol. 2, 535-562 (2014).

45. Yu, J. B. et al. Electroacupuncture ameliorates acute renal injury in lipopolysaccharide-stimulated rabbits via induction of HO-1 through the PI3K/Akt/Nrf2 pathways. PLoS One 10, e0141622 (2015)

46. Maurya, A. K. \& Vinayak, M. PI-103 and quercetin attenuate PI3K-AKT signaling pathway in T-Cell lymphoma exposed to hydrogen peroxide. PLoS One 11, e0160686 (2016).

47. Fathollah, S. et al. Investigation on the effects of the atmospheric pressure plasma on wound healing in diabetic rats. Sci. Rep. 6, 19144 (2016).

48. Isbary, G. et al. Successful and safe use of 2 min cold atmospheric argon plasma in chronic wounds: results of a randomized controlled trial. Br. J. Dermatol. 167, 404-410 (2012).

49. Grochot-Przeczek, A. et al. Heme oxygenase-1 accelerates cutaneous wound healing in mice. PLoS One. 4, e5803 (2009).

50. Brogliato, A. R. et al. Critical role of 5-lipoxygenase and heme oxygenase-1 in wound healing. J. Invest. Dermatol. 134, 1436-1445 (2014).

51. Cortas, N. K. \& Wakid, N. W. Determination of inorganic nitrate in serum and urine by a kinetic cadmium-reduction method. Clin. Chem. 36, 1440-1443 (1990).

\section{Acknowledgements}

This study was supported in part by JSPS KAKENHI to T.A., Grant Numbers 25108511, 15H00900, and 16K08914; and the Toukai Foundation for Technology to T.A. We thank Ayame Kano for her technical assistance.

\section{Author Contributions}

M.H. carried out the experiments and wrote the main manuscript; T.K. and H.H. analyzed and interpreted data; T.A. designed/supervised the study and wrote the manuscript.

\section{Additional Information}

Competing financial interests: The authors declare no competing financial interests.

How to cite this article: Horiba, M. et al. Cytoprotective effects of mild plasma-activated medium against oxidative stress in human skin fibroblasts. Sci. Rep. 7, 42208; doi: 10.1038/srep42208 (2017).

Publisher's note: Springer Nature remains neutral with regard to jurisdictional claims in published maps and institutional affiliations.

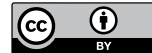

This work is licensed under a Creative Commons Attribution 4.0 International License. The images or other third party material in this article are included in the article's Creative Commons license, unless indicated otherwise in the credit line; if the material is not included under the Creative Commons license, users will need to obtain permission from the license holder to reproduce the material. To view a copy of this license, visit http://creativecommons.org/licenses/by/4.0/

(C) The Author(s) 2017 